\title{
Mesoglycan attenuates VSMC proliferation through activation of AMP-activated protein kinase and $\mathrm{mTOR}$
}

\author{
Kyung Young Lee ${ }^{1,3}$, Dong Hyup Lee ${ }^{2}$ and Hyoung Chul Choi ${ }^{1,3^{*}}$
}

\begin{abstract}
Background: Vascular smooth muscle cells (VSMC) proliferation contributes significantly to intimal thickening in atherosclerosis and restenosis diseases. Platelet derived growth factor (PDGF) has been implicated in VSMC proliferation though the activation of multiple growth-promoting signals. Mesoglycan, a natural glycosaminoglycans preparation, is reported to show vascular protective effect. However, the mechanisms by which mesoglycan inhibits proliferation of VSMC are not fully understood. Here, we investigated whether mesoglycan exert therapeutic effect via AMP-activated protein kinase (AMPK) and its underlying mechanism.

Methods: We cultured VSMC with increasing doses of mesoglycan. AMPK activation was measured by western blot analysis and cell proliferation was measured by flow cytometry.

Results: Mesoglycan dose- and time- dependently increased the phosphorylation of AMPK (Thr ${ }^{172}$ ) and its upstream target, LKB1 $\left(\mathrm{Ser}^{428}\right.$ ) and its downstream, ACC (Ser ${ }^{79}$ ) in VSMCs. Mesoglycan also blocked the PDGF-stimulated cell cycle progression through the $G_{0} / G_{1}$ arrest. AMPK DNa1, AMPK DNa2 or AMPK siRNA reduced the mesoglycan-mediated inhibition of VSMC proliferation. AMPK signaling activated by mesoglycan regulates mTOR phosphorylation which closely related to cell proliferation.

Conclusion: These data suggest that mesoglycan-induced AMPK activation suppress the VSMC proliferation via mTOR-dependent mechanism and mesoglycan may have beneficial effects on vascular proliferative disorders such as atherosclerosis.
\end{abstract}

Keywords: Mesoglycan, AMPK, VSMC, mTOR, Proliferation

\section{Background}

The proliferation of vascular smooth muscle cells (VSMC) is an important pathogenic factor in vascular disease such as atherosclerosis and hypertension [1-3]. Proliferation of VSMCs is activated by various growth factors, cytokines, and extracellular matrix components. Ultimately, mammalian target of rapamycin (mTOR) activity regulates both cell cycle progression and cell growth [4-6]. The vascular smooth muscle cell proliferation, elevated mTOR phosphorylation, an indicator of mTOR intrinsic catalytic

\footnotetext{
* Correspondence: hcchoi@med.yu.ac.kr

'Department of Pharmacology, College of Medicine, Yeungnam University, 170 Hyunchung-Ro, Nam-Gu, Daegu 42415, Republic of Korea

${ }^{3}$ Smart-aging Convergence Research Center, College of Medicine, Yeungnam

University, 170 Hyunchung-Ro, Daegu 42125, Republic of Korea

Full list of author information is available at the end of the article
}

activity [7]. Thus, inhibition of VSMC proliferation may reduce the development of vascular proliferative disease.

AMP-activated protein kinase (AMPK) is a serine/ threonine protein kinase, which serves as an energy sensor in all eukaryotic cell types. Published studies indicate that AMPK activation strongly suppresses cell proliferation in non-malignant cells as well as in tumor cells $[8,9]$. The importance of AMPK in cardiovascular functions is best demonstrated by recent studies showing that widely used drugs, including statins, metformin and rosiglitazone, execute cardiovascular protective effects at least partly through the activation of AMPK [10-12]. Among these, research on the protective actions of and the regulation of energy metabolism by AMPK in the vascular smooth muscle is becoming an important area. Therefore, we focus on the effect of AMPK activation on 
cellular proliferation and discuss the possibility that AMPK might be a therapeutic target for proliferative disorders such as atherosclerosis and cancers.

Mesoglycan is a mucopolysaccharide complex that is extracted from calf aorta. Aortic glycosaminoglycans and mucopolysaccharides such as mesoglycan are used to treat diseases of blood vessel homeostasis, blood clotting, atherogenesis, and atherosclerosis [13, 14]. Mesoglycan is composed of heparan sulfate, dermatan sulfate, heparin and minimal quantities of chondroitin sulfate [15]. One of the components that heparan sulfate proteoglycan is reported to inhibit the growth of VSMC in culture [16, 17]. Natural glycosaminoglycans such as heparin are also known to inhibit VSMC proliferation in vitro in tissue culture and in vivo in animal models [18-20]. Therefore, we hypothesized that mesoglycan may has the anti-proliferative effects in VSMCs.

Recent study has demonstrated that glucosamine suppress adipocyte differentiation and adipogenesis through the up-regulation of AMPK pathway [21]. Hence, the purpose of this study is to determine whether mesoglycan can induce AMPK activation in VSMCs and to determine whether mesoglycan-induced AMPK activation inhibits cell proliferation via an mTOR-dependent mechanism.

\section{Methods}

\section{Materials}

Mesoglycan was kindly provided from Chodang Pham. CO.. Dulbecco's modified eagle medium (DMEM) and fetal bovin serum (FBS) were purchased from Thermo Scientific (Logan, UT, U.S.A.). Pro-prep protein extract buffer was purchased from Intron Biotechnology (Sungnam, Korea). Antibodies against LKB1, phospho-LKB1 $\left(\mathrm{Ser}^{428}\right)$, AMPK, phospho-AMPK ( $\left.\mathrm{Thr}^{172}\right)$, phospho-ACC $\left(\mathrm{Ser}^{79}\right), \mathrm{mTOR}$, phospho-mTOR $\left(\mathrm{Ser}^{2448}\right)$, Bcl-2, Bax, phospho-p70S6K $\left(\mathrm{Thr}^{389}\right)$ and phospho-4EBP1 $\left(\mathrm{Ser}^{65}\right)$ were purchased from Cell Signaling Technology (Beverly, MA, U.S.A.). A monoclonal antibody against $\beta$-actin was purchased from SigmaAldrich (St. Louis, MO). Compound C, AMPK inhibitor, was provided by Calbiochem (La Jolla, CA, U.S.A.). Human Platelet-Derived Growth Factor BB was purchased from Cell Signaling Technology (Beverly, MA, U.S.A.). AMPK siRNA, Raptor siRNA, Control siRNA, p53, p27, p21, PCNA and Cytochrome $\mathrm{C}$ were purchased from Santa Cruz Biotechnology (Santa Cruz, CA, U.S.A.).

\section{Cell culture}

Sprague-Dawley rats (SD rats) were anesthetized with pentobarbital $(50 \mathrm{mg} / \mathrm{kg})$. Vascular smooth muscle cells (VSMCs) were isolated from thoracic aorta and the connective tissue was removed. Aortic VSMCs were grown in DMEM with $10 \% \mathrm{FBS}$ and $1 \%$ antibiotic (penicillin $10000 \mathrm{U} / \mathrm{ml}$ ). It was processed using a $1 \mathrm{~mm}$ chop setting in a $10 \mathrm{~cm}$ culture dish, and cultured with $50 \%$
FBS-DMEM with $1 \%$ antibiotics and incubated in a $\mathrm{CO}_{2}$ incubator $\left(95 \% \mathrm{CO}_{2}\right.$ air, $\left.37{ }^{\circ} \mathrm{C}\right)$. We used VSMCs from 6 to 8 passages at $70-90 \%$ confluence in $10 \mathrm{~cm}$ dishes, and cell growth was arrested by incubation of the cells in serum-free DMEM for $24 \mathrm{~h}$ prior to use.

\section{Western blot analysis}

Whole cell extracts were prepared by lysing the cells in pro-prep protein extract buffer. The protein concentration was quantified with protein assay reagent from Bio-Rad (Hercules, CA, U.S.A.). Equal amounts of protein were mixed with Laemmli Sample Buffer (Bio-Rad) and heated for $5 \mathrm{~min}$ at $100{ }^{\circ} \mathrm{C}$ before loading. Total protein samples $(30 \mu \mathrm{g})$ were subjected to $10 \%$ SDS-polyacrylamide gel electrophoresis (SDS-PAGE) for $1 \mathrm{~h} 30 \mathrm{~min}$ at $100-120 \mathrm{~V}$. The separated proteins were electrophoretically transferred onto a PVDF membrane for $1 \mathrm{~h} 20 \mathrm{~min}$ at $100 \mathrm{~V}$ using SD Semi-dry Transfer Cell. The membranes were blocked with $5 \%$ non-fat milk in PBS containing $0.05 \%$ Tween 20 (PBS-T) for $1 \mathrm{~h}$ at room temperature. The membranes were then incubated with the primary antibodies at a dilution of $1: 1000$ by overnight at $4{ }^{\circ} \mathrm{C}$ in PBST. The membranes were then washed with four changes of wash buffer $(0.05 \%$ Tween 20 in PBS) and incubated for $1 \mathrm{~h}$ at room temperature in PBS containing antirabbit(Stress-gen, Ann Arbor, MI, USA) and anti-mouse IgG (Sigma, St. Louis, MO, USA) antibodies. Finally, after three more rinses with wash buffer, the membranes were exposed to ECL and ECL Plus western blot analysis detection reagents.

\section{Transfection of siRNA}

Transfection of VSMCs with siRNA was performed using lipofectamine-2000 reagent, according to the manufacturer's instructions. Aliquots of $1 \times 10^{4}$ cells were plated on 6 well on the day before the transfection and grown to about $70 \%$ confluence. The cells were then transfected with $10 \mu \mathrm{M}$ AMPK siRNA (Santa Cruz Biotechnology Inc., Santa Cruz, CA) +100 pmol of Lipofectamine for $6 \mathrm{~h}$ in Opti-MEM ${ }^{\circ}$ reduced serum medium (Invitrogen, Carlsbad, CA, USA). Following an incubation period of $48 \mathrm{~h}$, the AMPK protein level was measured using western blot analysis, and cell proliferation was analyzed using the MTT assay.

\section{Adenoviral transduction}

Adenoviruses expressing the control gene GFP, the dominant-negative isoform of the $\alpha 1$ and $\alpha 2$ subunits of AMPK (AMPK DN 1 and $\mathrm{DN} \alpha 2$ ) were amplified in AD293 cells using standard methodologies. The transductions were carried out in VSMC in sereum-fress DMEM for $6 \mathrm{~h}$. 
Flow cytometric analysis for apoptosis and cell cycle Apoptosis was examined by Annexin V-fluorescein isothiocyanate (FITC) staining (BD Biosciences, San Jose, CA, U.S.A.) according to the manufacturer's instructions. Cells were seeded on 6-well plates and incubated for 2 days. Cells were treated with mesoglycan $(0.1 \mu \mathrm{g} / \mathrm{ml})$ for $24 \mathrm{~h}$. The FITC fluorescence intensity of 10,000 cells was measured using a Becton-Dickinson FACS Caliber flow cytometer (BD Biosciences). Cell cycle profiles were analyzed by propidium iodide (PI) staining. A minimum of 10,000 cells in each sample was detected according to intracellular PI fluorescence intensity by flow cytometry, and cell cycle was analyzed by Cell Quest software (BD Biosciences).

\section{Fluorescence intensity measurements}

Cells were washed and then maintained in complete medium. After detachment from dishes with $50 \mathrm{mM}$
EDTA, the cells were centrifuged at $3000 \mathrm{rpm}$ for 10 min and resuspended in PBS containing $2 \%$ bovine serum albumin. After labeling, cells were washed once in PBS, fixed in $4 \%$ paraformaldehyde, and analyzed on a flow cytometer. For each sample, 1000 cells were analyzed, and the results were expressed as geometric mean fluorescence.

\section{Immunofluorescence analysis}

VSMCs were seeded on coverslips in $35 \mathrm{~mm}$ glass bottom dishes, fixed in $4 \%$ formaldehyde, and permeabilized with $0.2 \%$ Triton X-100. The p-mTOR primary antibody was used at 1:100 (Santa Cruz Biotechnology) and incubated with cells overnight at $4{ }^{\circ} \mathrm{C}$. Rabbit FITC secondary antibody (Invitrogen) was used at 1:100 and incubated with cells for $1 \mathrm{~h}$ at room temperature. Fixed and immunofluorescently stained cells were imaged using a Leica confocal microscope (Bannockburn, IL, USA).

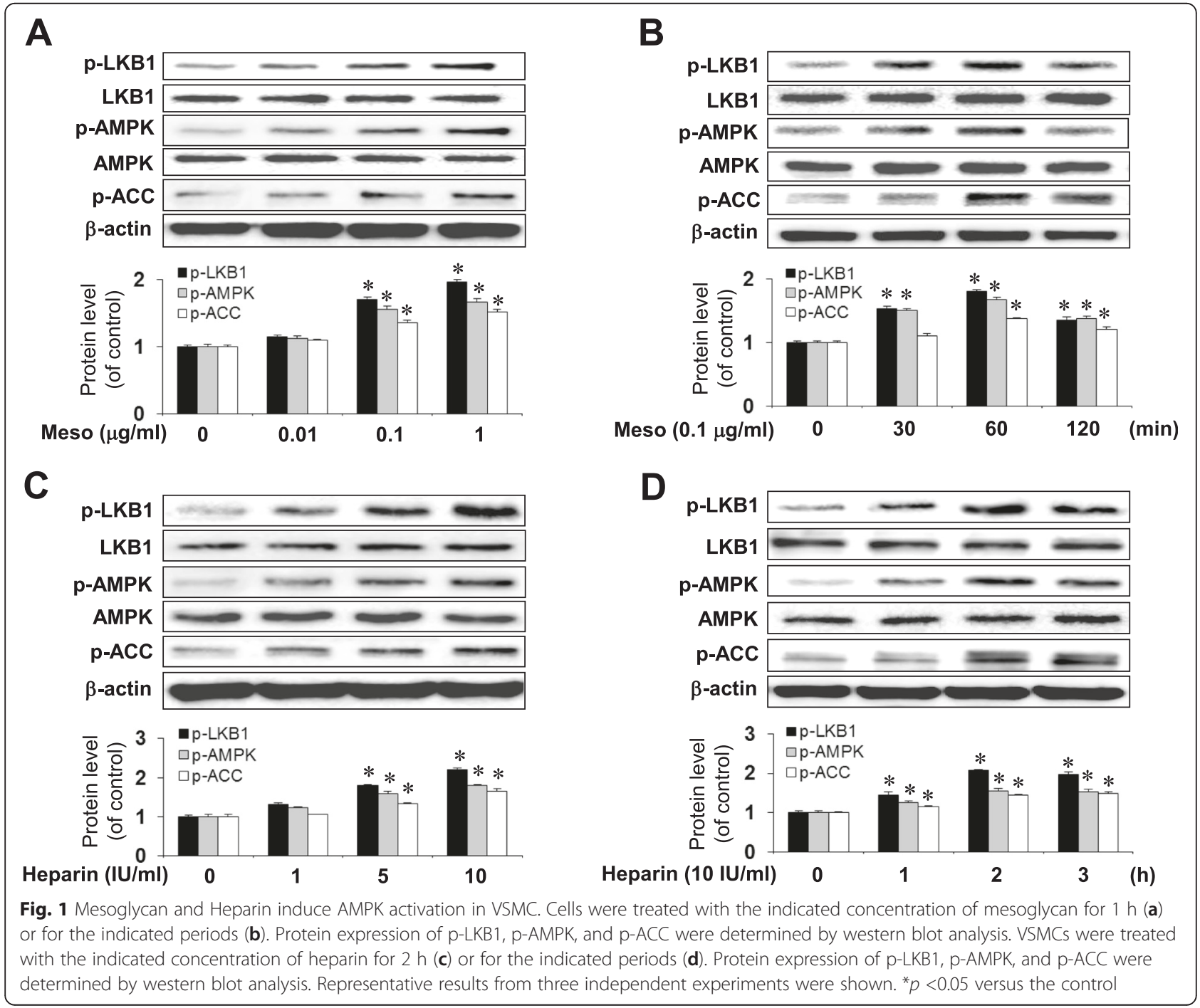




\section{Cell proliferation assay}

VSMCs were seeded on 24-well plates at $1 \times 10^{4}$ cells per well in DMEM supplemented with $10 \% \mathrm{FBS}$. After different treatments, $50 \mu \mathrm{l}$ of $1 \mathrm{mg} / \mathrm{ml} \mathrm{MTT} \mathrm{solution}$ was added to each well $(0.1 \mathrm{mg} /$ well $)$ and incubated for $4 \mathrm{~h}$. The supernatants were aspirated, and the formazan crystals in each well were solubilized with $200 \mu \mathrm{l}$ dimethyl sulfoxide (DMSO). An aliquot of this solution $(100 \mu \mathrm{l})$ was placed in 96-well plates. Cell proliferation was assessed by measuring the absorbance at $570 \mathrm{~nm}$ using a microplate reader.

\section{Statistical analysis}

Results are expressed as mean \pm SEM from at least three independent experiments. Differences between data sets were assessed by one-way analysis of variance (ANOVA) or Bonferroni's test.

\section{Results}

Mesoglycan and heparin increased phosphorylation of LKB1, AMPK and ACC in VSMCs

Mesoglycan $(0.01-1 \mu \mathrm{g} / \mathrm{ml}$ for $1 \mathrm{~h})$ produced a dosedependent increase in phosphorylation of LKB1 at $\mathrm{Ser}^{428}$, AMPK at $\mathrm{Thr}^{172}$ and of ACC at $\mathrm{Ser}^{79}$ in VSMCs (Fig. 1a). Compared with control, mesoglycan $(0.1 \mu \mathrm{g} / \mathrm{ml}$, $1 \mathrm{~h}$ ) caused a drastic increase in phosphorylation of LKB1 $\left(\mathrm{Ser}^{428}\right)$, AMPK $\left(\mathrm{Thr}^{172}\right.$ ) and ACC $\left(\mathrm{Ser}^{79}\right)$ (Fig. 1b).

We next examined whether heparin was correlated with AMPK activity. Heparin (1-10 IU/ml for $2 \mathrm{~h}$ ) produced a dose-dependent increase in phosphorylation of

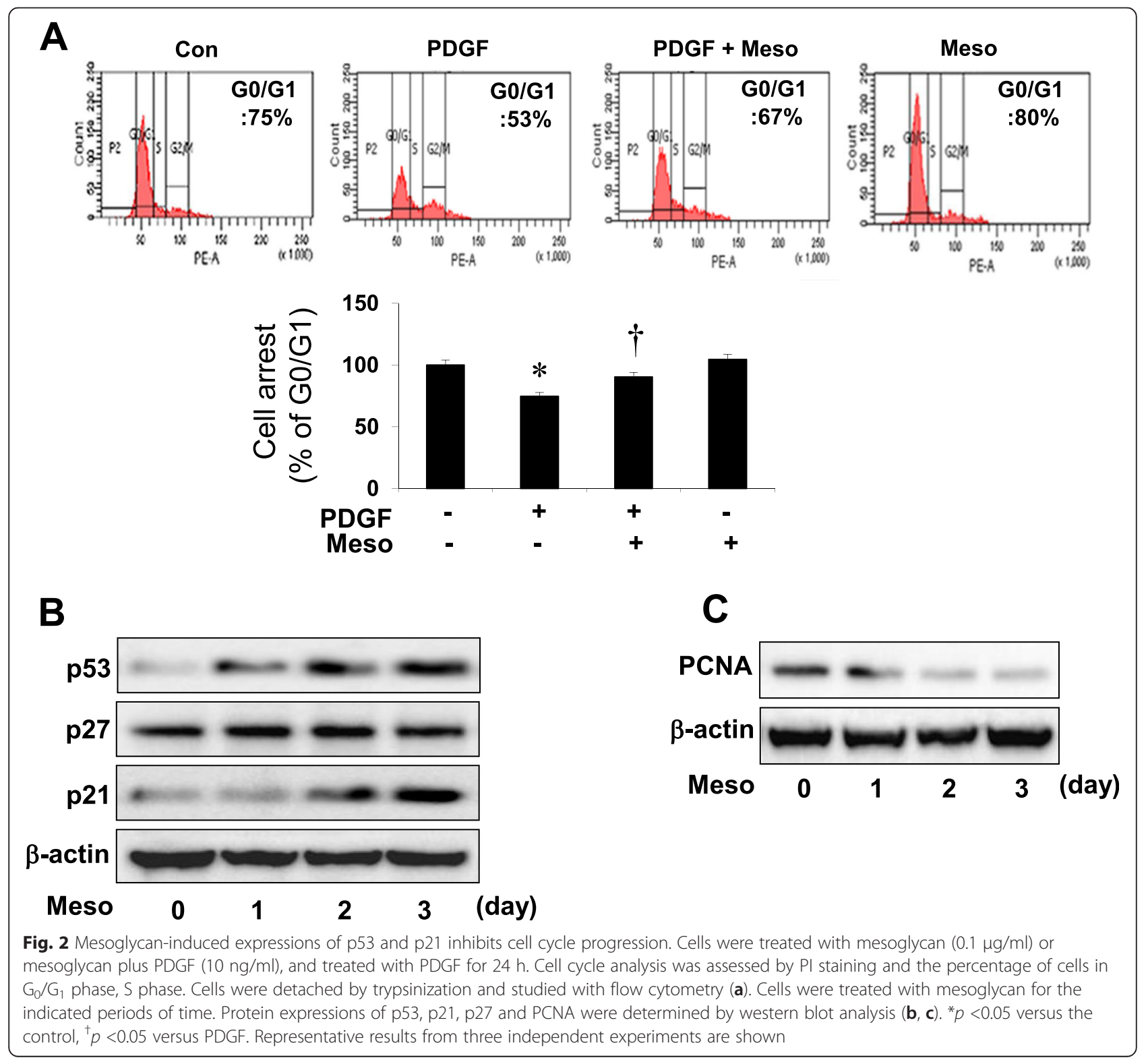


LKB1 at $\mathrm{Ser}^{428}$, AMPK at $\mathrm{Thr}^{172}$ and of ACC at $\mathrm{Ser}^{79}$ in VSMCs (Fig. 1c). Compared with control, heparin (10 IU/ $\mathrm{ml}, 2 \mathrm{~h}$ ) caused a significant increase in phosphorylation of LKB1 $\left(\mathrm{Ser}^{428}\right)$, AMPK $\left(\mathrm{Thr}^{172}\right)$ and ACC $\left(\mathrm{Ser}^{79}\right)$ (Fig. 1d). These data suggest that mesoglycan and heparin induced the dose-and time-dependent phosphorylation of LKB1, AMPK and ACC.

\section{PDGF-induced cell cycle progression in $G_{2} / M$ phase is reversed by mesoglycan}

We examined the effect of mesoglycan on cell cycle progression using flow cytometric analysis with PI staining. After serum deprivation for $48 \mathrm{~h}$, growth-arrested VSMC were treated with mesoglycan $(0.1 \mu \mathrm{g} / \mathrm{ml})$ and PDGF $(10 \mathrm{ng} / \mathrm{ml})$. Compared with PDGF-treated cells, mesoglycan increased the number of cells in the $G_{0} / G_{1}$ phase (Fig. 2a).

We then examined the effect of mesoglycan on the expression of p53, a key regulator of the cell cycle, as well as p21 and p27, downstream targets of p53. Mesoglycan increased p53 and p21 expression in a time-dependent manner, whereas the levels of p27 were not changed (Fig. 2b). Next, we examined the effect of mesoglycan on the expression of proliferating cell nuclear antigen (PCNA). Mesoglycan decreased PCNA expression in a time-dependent manner (Fig. 2c). These data suggest that mesoglycan blocks VSMC proliferation by increasing $\mathrm{G}_{0} / \mathrm{G}_{1}$ arrest and decreasing $\mathrm{G}_{2} / \mathrm{M}$ phase.

\section{Mesoglycan-induced expression of $p 53$ and $p 21$ did not affect the apoptotic pathway in VSMCs}

The reduction in cell number induced by mesoglycan could result from either an increase in cell death or inhibition of proliferation. Thus, we examined whether mesoglycan could induce apoptosis. Apoptosis was measured by flow cytometric analysis with annexin $\mathrm{V}$ staining after mesoglycan treatment. Compared with control, mesoglycan-treated cells induced non-apoptotic cell death (Fig. 3a).

We then examined the effect of mesoglycan on the expression of the apoptotic pathway. There was no change in the protein levels of $\mathrm{Bcl}-2, \mathrm{Bax}$, cytochrome $\mathrm{C}$ and

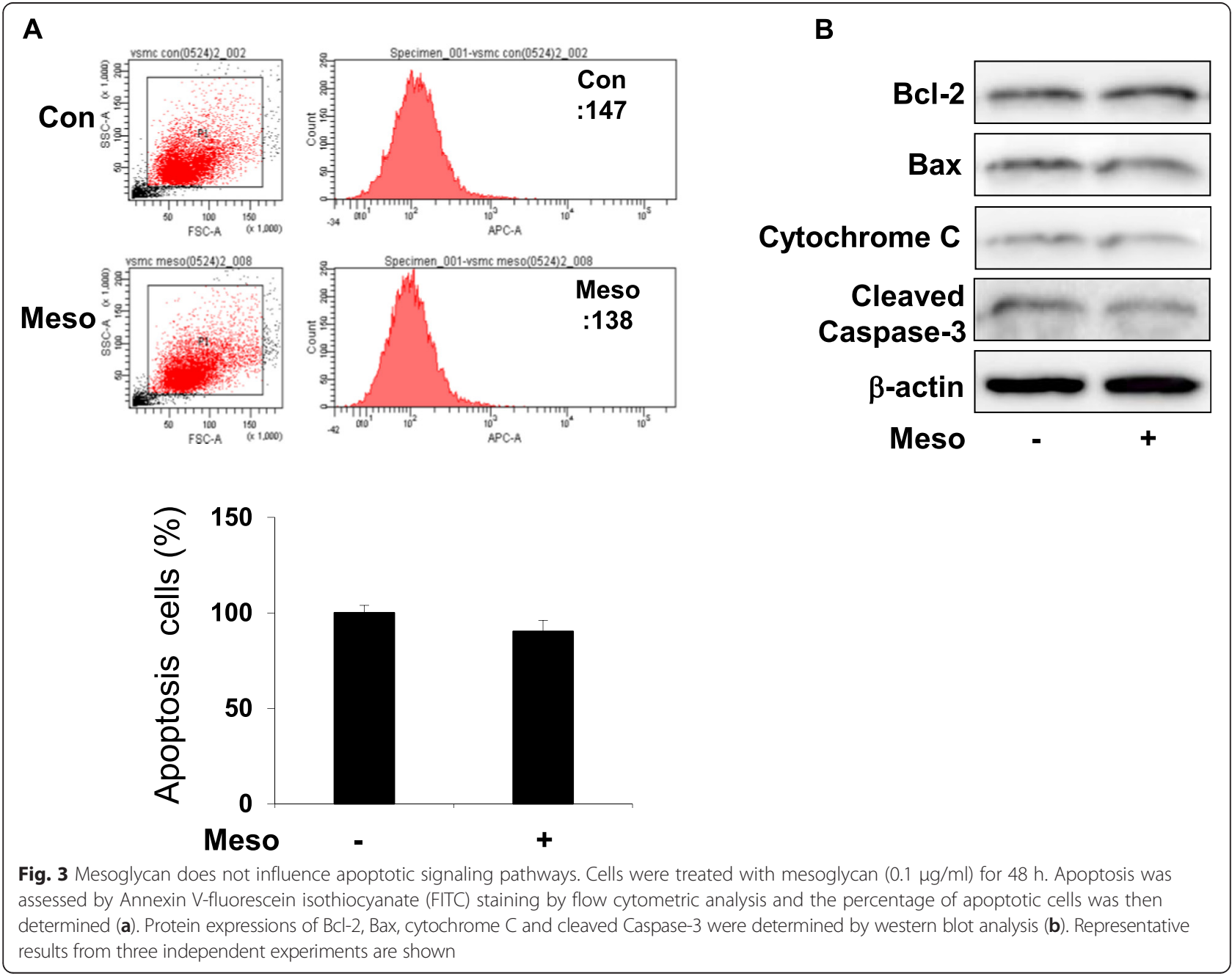


cleaved caspase-3 (Fig. 3b). These data suggest that the reduction in cell number induced by mesoglycan is not apoptotic cell death.

\section{Mesoglycan inhibited mTOR signaling through AMPK activation in VSMC}

mTOR protein kinase has the potential to regulate the $G_{1}$ phase of the cell cycle and to stimulate cell proliferation [22]. We examined whether mTOR signaling is involved in mesoglycan-induced AMPK pathway. As shown in Fig. 4a, AMPK siRNA transfection significantly inhibited p-AMPK and total AMPK. In addition, phosphorylation of mTOR, p70S6K and 4EBP1 increased. Continuously, the adenovirus-mediated overexpression system was used to determine whether mesoglycan-induced AMPK activation could inhibit mTOR pathway. Compared to the GFP controls, transduction of AMPK

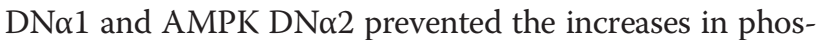
phorylation of the AMPK (Fig. 4b). Additionally, as shown in Fig. 4c, we examined the effects of raptor siRNA on mesoglycan-inhibited mTOR signaling. These data suggested that the mesoglycan/AMPK pathway negatively regulates mTOR phosphorylation in VSMCs.

\section{Inhibition of AMPK activation increased mTOR} phosphorylation in VSMC

To further test whether mesoglycan-induced AMPK activity negatively regulates mTOR phosphorylation, cultured cells were treated with compound $\mathrm{C}$ and transfected with AMPK siRNA and then stained with p-mTOR specific antibodies. Immunofluorescence with the p-mTOR antibodies revealed changes in mTOR phosphorylation in compound C-treated and AMPK siRNA transfected cells compared to PDGF plus mesoglycan (Fig. 5a). In the next set of experiments, we examined this in flow cytometry studies. This analysis showed that the level of p-mTOR decreased approximately $30 \%$ in cells incubated with mesoglycan compared to that in PDGF alone treatment (Fig. 5b).

We then examined the effect of mesoglycan on the PDGF induced VSMC proliferation. Mesoglycan decreased VSMC proliferation stimulated with PDGF. Compound C, a specific inhibitor of AMPK, reduced the mesoglycanmediated inhibition of VSMC proliferation. Genetic inhibition of AMPK with siRNA also restored the mesoglycan induced anti-proliferative effect (Fig. 5c). These data suggest that AMPK signaling activated by mesoglycan regulates mTOR phosphorylation related to cell proliferation.
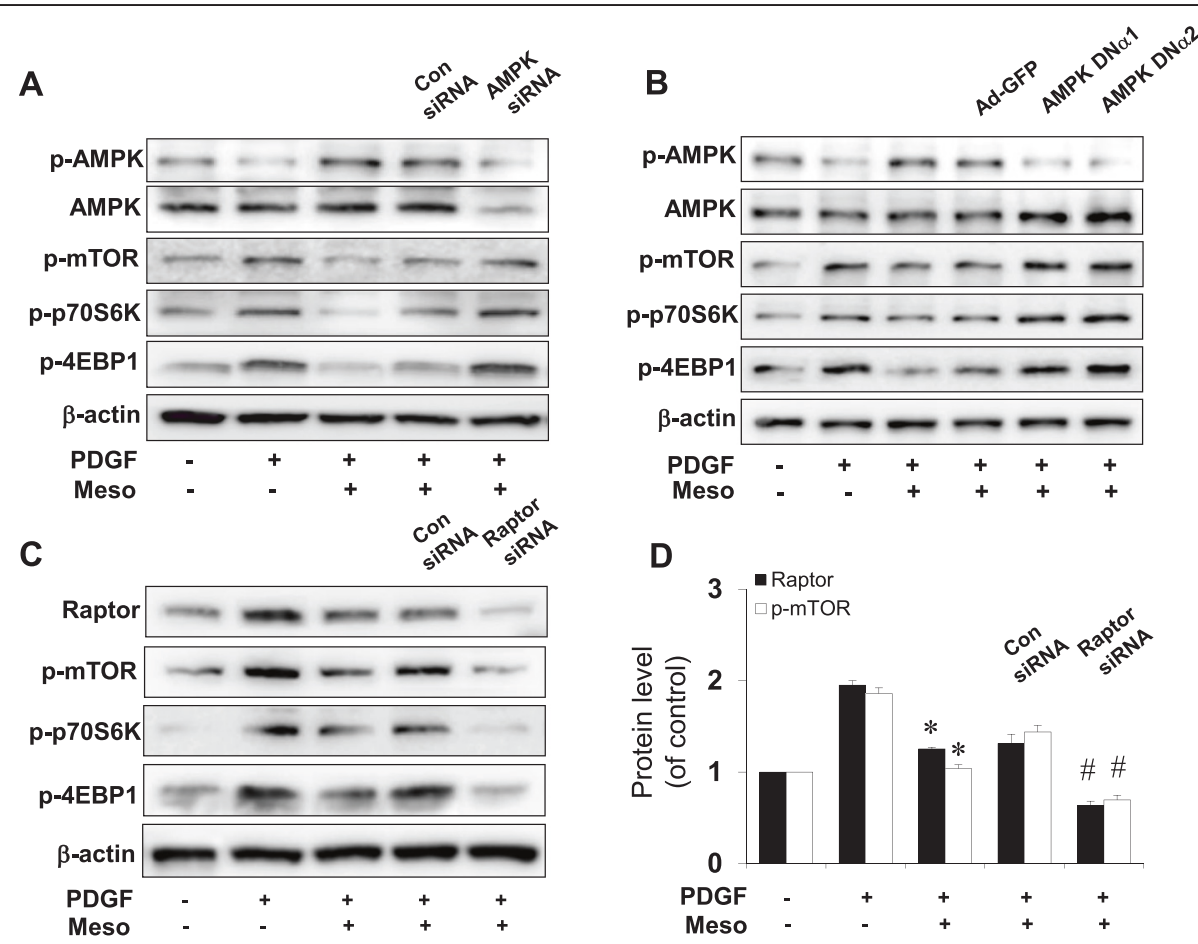

Fig. 4 AMPK signaling regulates expressions of p-mTOR and its downstream. VSMCs were stimulated with PDGF for $24 \mathrm{~h}$ and then transfected with control (Con) siRNA or AMPK siRNA in the presence of mesoglycan. Protein expression of p-AMPK, AMPK, p-mTOR, p-p70S6K and p-4EBP1 were determined by western blot analysis (a). VSMCs were transfected with adenovirus-GFP, AMPK DNa1 and AMPK DNa2 for 6 h and then incubated for $48 \mathrm{~h}$. The levels of p-AMPK, AMPK, p-mTOR, p-p70S6K and p-4EBP1 were determined by western blot analysis (b). VSMCs were stimulated with PDGF for $24 \mathrm{~h}$ and then transfected with control (Con) siRNA or Raptor siRNA in the presence of mesoglycan. VSMCs were subjected to western blotting to determine the level of Raptor, p-mTOR, p-70S6K and p-4EBP1 proteins (c). Densitometric analysis of Raptor and p-mTOR expressions in $4 C$ (d). ${ }^{*} p \leq 0.05$ versus PDGF, ${ }^{*} p \leq 0.05$ versus PDGF \pm Meso. Representative results from three independent experiments are shown 


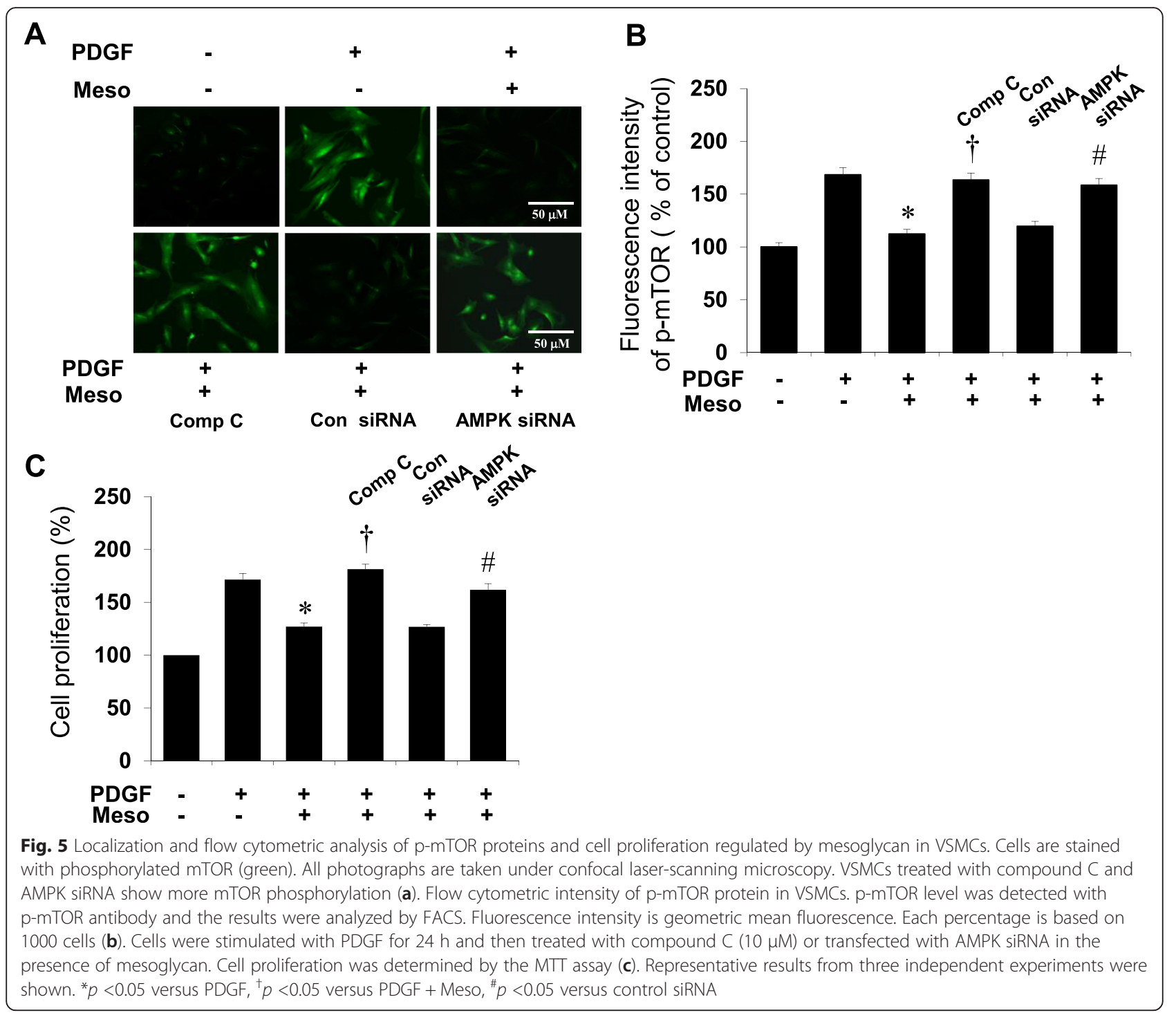

\section{Discussion}

Mesoglycan has been shown to decrease capillary permeability to enhance systemic fibrinolysis in humans and to prevent venous thrombus formation in experimental and clinical settings [23]. But the exact mechanisms underlying the proliferation by mesoglycan in VSMC are still unknown. Metabolic cardiovascular disease is closely regulated through the mTOR signaling pathways [24, 25]. Activation of pathways of mTOR also may promote tumor growth [26] and increase the activation of imflammatory cell pathways $[27,28]$ that may negatively impact the cardiovascular system.

The main purpose of the present study was to demonstrate the anti-proliferative mechanism of mesoglycan in VSMC, specifically focused on the AMPK activation. Also, the exact mechanisms underlying the anti-proliferation by mesoglycan-induced AMPK activation in VSMC are still unknown.
In the present study, we first demonstrated that mesoglycan and heparin activated AMPK by phosphorylating AMPK $\left(\mathrm{Thr}^{172}\right.$ ) in VSMC (Fig. 1). Mesoglycan also increased phosphorylation of LKB1, an upstream substrate of AMPK $\left(\mathrm{Ser}^{428}\right)$, and phosphorylation of ACC, a downstream substrate of AMPK $\left(\mathrm{Ser}^{79}\right)$. Mesoglycaninduced AMPK activation has an attractive characteristic, because AMPK is reported to mediate beneficial and bioprotective effects of metformin [29] and adiponectin [30]. AMPK is a serine/threonine protein kinase, which serves as an energy sensor in eukaryotic cells. Several studies have revealed that AMPK activation suppresses cell proliferation in normal cells as well as in tumor cells [31].

In the current study, we found that the anti-proliferative effect of mesoglycan might be in part via an AMPK-p53p21 signaling pathway. The mechanism of growth suppression by mesoglycan is there $G_{0} / G_{1}$ cell cycle arrest (Fig. 2). These effects of AMPK are mediated through 
multiple mechanisms including cell cycle regulation and inhibition of protein synthesis. AMPK activation by AICAR or constitutively activated AMPK induces a $G_{0} / G_{1}$ cell cycle arrest via AMPK-dependent phosphorylation of p53 in human VSMCs [32].

Mesoglycan-induced expression of p53 and p21 does not change the apoptotic pathway in VSMCs (Fig. 3). The reduction in cell number induced by mesoglycan not increase in cell death but inhibition of proliferation.

Furthermore, several studies revealed that endothelial cells cultured from fetal bovine pulmonary arteries produce a basement membrane heparan sulfate proteoglycan that is a potent inhibitor of smooth muscle proliferation $[33,34]$. In this regard, we examined whether mesoglycan can impede VSMC proliferation through activation of AMPK, because pharmacologic and genetic inhibition of AMPK restored the mesoglycan-mediated inhibition of VSMC proliferation. AMPK inhibition by AMPK siRNA prevented mesoglycan-induced phosphorylation of AMPK. AMPK inhibition by adenoviral infection encoding dominant-negative form of AMPK exhibited the increases in p-AMPK. These results confirmed that anti-proliferative effect of mesoglycan is mediated in part by an AMPK signaling pathway (Fig. 4).

In the cardiovascular and metabolic systems, mTOR and its multi-protein complexes of TORC1 and TORC2 regulate insulin release, cell growth and cardiomyocyte proliferation [35]. Our findings suggested that mesoglycan inhibited mTOR signaling and cell proliferation through AMPK pathway in VSMCs (Fig. 5).

Taken together, inhibition of mTOR signaling by mesoglycan-induced AMPK activation could induce the anti-proliferative mechanism of mesoglycan in VSMC.

\section{Conclusion}

In this study, mesoglycan-induced AMPK activation inhibited the PDGF-induced VSMC proliferation via an mTOR-dependent mechanism. Our observations also indicate that mesoglycan-induced AMPK activation may have beneficial effects on vascular proliferative disorders such as atherosclerosis.

\section{Abbreviations}

AMPK: AMP-activated protein kinase; mTOR: Mammalian target of rapamycin; PDGF: Platelet derived growth factor; VSMC: Vascular smooth muscle cells.

\section{Competing interests}

The authors declare that they have no competing interests.

\section{Authors' contributions}

KYL carried out experimental molecular studies and drafted the manuscript. $\mathrm{DHL}$ carried out the molecular studies, participated in the design of the study and the sequence alignment. HCC conceived of the study and participated in its design and coordination. All authors read and approved the final manuscript.

\section{Acknowledgements}

This study was supported by Academic-Industrial Cooperative Research Fund of Korean Society of Hypertension (2014).

\section{Author details}

'Department of Pharmacology, College of Medicine, Yeungnam University, 170 Hyunchung-Ro, Nam-Gu, Daegu 42415, Republic of Korea. ${ }^{2}$ Department of Thoracic and Cardiovascular Surgery, College of Medicine, Yeungnam University, 170 Hyunchung-Ro, Nam-Gu, Daegu 42415, Republic of Korea.

${ }^{3}$ Smart-aging Convergence Research Center, College of Medicine, Yeungnam University, 170 Hyunchung-Ro, Daegu 42125, Republic of Korea.

Received: 10 September 2015 Accepted: 8 January 2016

Published online: 18 January 2016

\section{References}

1. Ross R. Cell biology of atherosclerosis. Annu Rev Physiol. 1995;57:791-804.

2. Owens GK, Kumar MS, Wamhoff BR. Molecular regulation of vascular smooth muscle cell differentiation in development and disease. Physiol Rev. 2004:84:767-801.

3. Gorenne I, Kavurma M, Scott S, Bennett M. Vascular smooth muscle cell senescence in atherosclerosis. Cardiovasc Res. 2006;72:9-17.

4. Laplante M, Sabatini DM. mTOR signaling at a glance. J Cell Sci. 2009;122:3589-94.

5. Krymskaya VP, Goncharova EA. PI3K/mTORC1 activation in hamartoma syndromes: therapeutic prospects. Cell Cycle. 2009;8:403-13.

6. Krymskaya VP, Snow J, Cesarone G, Khavin I, Goncharov DA, Lim PN, et al. mTOR is required for pulmonary arterial vascular smooth muscle cell proliferation under chronic hypoxia. FASEB J. 2011;25:1922-33.

7. Soliman GA, Acosta-Jaquez HA, Dunlop EA, Ekim B, Maj NE, Tee AR, et al. mTOR ser-2481 Autophosphorylation Monitors mTORC-specific Catalytic Activity and Clarifies Rapamycin Mechanism of Action. J Biol Chem. 2010;285:7866-79.

8. Sung JY, Choi HC. Nifedipine inhibits vascular smooth muscle cell proliferation and reactive oxygenspecies production through AMP-activated protein kinase signaling pathway. Vasc Pharmacol. 2012;56:1-8.

9. Nagata D, Takeda R, Sata M, Satonaka H, Suzuki E, Nagano T, et al. AMPactivated protein kinase inhibits angiotensin $\mathrm{I}$ - stimulated vascular smooth muscle cell proliferation. Circ. 2004;110:444-51.

10. Choi HC, Song $P$, Xie Z, Wu Y, Xu J, Zhang M, et al. Reactive nitrogen species is required for the activation of the AMP-activated Protein Kinas by statin in vivo. J Biol Chem. 2008;283:20186-97.

11. Morrison A, Yan X, Tong C, Li J. Acute rosiglitazone treatment is cardioprotective against ischemia-reperfusion injury by modulating AMPK, Akt, and JNK signaling in nondiabetic mice. Am J Physiol Heart Circ Physiol. 2011;301:895-902.

12. Fryer LG, Parbu-Patel A, Carling D. The anti-diabetic drugs rosiglitazone and metfortmin stimulate AMP-activated protein kinas through distinct signaling pathways. J Biol Chem. 2002;277:25226-32.

13. Wagner WD. Proteoglycan structure and function as related to atherosclerosis. Ann N Y Acad Sci. 1985:454:52-68.

14. Little PJ, Ballinger ML, Osman N. Vascular wall proteoglycan synthesis and structure as a target for the prevention of atherosclerosis. Vasc Health Risk Manag. 2007;3:117-24.

15. Tufano A, Arturo C, Cimino E, Di Minno MN, Di Capua M, Cerbone AM, et al. Mesoglycan: Clinical evidences for use in vascular disease. Int J Vasc Med. 2010;390643.

16. Bingley JA, Hayward IP, Campbell JH, Campbell GR. Arterial heparin sulfate proteoglycans inhibit vascular smooth muscle cell proliferation and phenotype change in vitro and neointimal formation in vivo. J Vasc Surg. 1998:28:308-18.

17. Koyama N, Kinsella MG, Wight TN, Hedin U, Clowes AW. Heparan sulfate proteoglycans mediate a potent inhibitory signal for migration of vascular smooth muscle cells. Circ Res. 1998:83:305-13.

18. Kazi M, Lundmark K, Religa P, Gouda I, Larm O, Ray A, et al. Inhibition of rat smooth muscle cell adhesion and proliferation by non-anticoagulant heparins. J Cell Physiol. 2002;193:365-72.

19. Clowes AW, Karnowsky MJ. Suppression by heparin of smooth muscle cell proliferation in injured arteries. Nature. 1977;265:625-6.

20. Rosenberg RD, Fritze LM, Castellot Jr JJ, Kamovsky MJ. Heparin-like molecules as regulators of atherogenesis. Nouv Rev Fr Hematol. 1984;26:255-60. 
21. Kong CS, Kim JA, Kom SK. Anti-obesity effect of sulfated glucosamine by AMPK signal pathway in 3T3-L1 adipocytes. Food Chem Toxicol. 2009:47:2401-6.

22. Bilogen E, Brian M, Jennifer AK, Edward PF, Diane CF. mTOR Kinase Domain Phosphorylation Promotes mTORC1 Signaling, Cell Growth, and Cell Cycle Progression. Mol Cell Biol. 2011;31:2787-801.

23. Bianchini P, Osima B, Parma B, Nader HB, Dietrich CP. Lack of correlation between in vitro and in vivo antithrombotic activity of heparin fractions and related copounds. Heparan sulfate as an antithrombotic agent in vivo. Thromb Res. 1985;40:597-607.

24. Chong ZZ, Shang YC, Maiese K. Cardiovascular disease and mTOR signaling. Trends Cardiovasc Med. 2011;21:151-5.

25. McMullen JR, Sherwood MC, MBBS, FRACP, Tarnavski O, Zhang L, Dorfman AL, et al. Inhibition of mTOR Signaling With Rapamycin Regresses Established Cardia Hypertrophy Induced by Pressure Overload. Circulation. 2004;109:3050-5.

26. Roulin D, Cerantola Y, Dormond-Meuwly A, Demartines N, Dormond O. Targeting mTOR2 inhibits colon cancer cell proliferation in vitro and tumor formation in vivo. Mol Cancer. 2010;9:57.

27. Dello Russo C, Lisi I, Tringali G, Navarra P. Involvement of mTOR kinase in cytokine-dependent microglial activation and cell proliferation. Biochem Pharmacol. 2009;78:1242-51.

28. Poulose SM, Bielinski DF, Carrihill-Knoll K, Rabin BM, Shukitt-Hale B. Exposure to O-Particle Radiation Causes Aging-Like Decrements in Rats through Increased Oxidative Stress, Inflammation and Loss of Autophagy. Radiat Res. 2011;176:761-9.

29. Zhou G, Myers R, Li Y, Chen Y, Shen X, Fenyk-Melody J, et al. Role of AMPactivated protein kinase in mechanism of metformin action. J Clin Invest. 2001;108:1167-74.

30. Yamauchi T, Kamon J, Minokoshi Y, Ito Y, Waki H, Uchida S, et al. Adiponectin stimulates glucose utilization and fatty-acid oxidation by activating AMP-activated protein kinase. Nat Med. 2002;8:1288-95.

31. Motoshima H, Goldstein BJ, Igata M, Araki E. AMPK and cell proliferation-AMPK as a therapeutic target for atherosclerosis and cancer. J Physiol. 2006;574:63-71.

32. Igata M, Motoshima H, Tsuruzoe K, Kojima K, Matsumura T, Kondo T, et al. Adenosine monophosphate-activated protein kinase suppresses vascular smooth muscle cell proliferation through the inhibition of cell cycle progression. Circ Res. 2005;97:837-44.

33. William EB, Richard TK, Clay MA, Diane EL, Merton B. Endothelial Heparan Sulfate Proteoglycan. I. Inhibitory Effects on Smooth Muscle Cell Proliferation. Am J Respir Cell Mol Biol. 1990;2:13-24.

34. Claudia Magdalena C, Montserrat Cecilia C, Roberto Miguel M, Norma RR. Proteoglycan Production by Vascular Smooth Muscle Cells From Resistance Arteries of Hypertensive Rats. Hypertension. 1999;34:893-6.

35. Chong ZZ, Maiese K. Mammalian target of rapamycin signaling in diabetic cardiovascular disease. Cardiovasc Diabetol. 2012;11:45.

\section{Submit your next manuscript to BioMed Central and we will help you at every step:}

- We accept pre-submission inquiries

- Our selector tool helps you to find the most relevant journal

- We provide round the clock customer support

- Convenient online submission

- Thorough peer review

- Inclusion in PubMed and all major indexing services

- Maximum visibility for your research

Submit your manuscript at www.biomedcentral.com/submit
C Biomed Central 